Do dyslexics have auditory input processing difficulties?

Poulsen, Mads

Published in:

Applied Psycholinguistics

DOI:

10.1017/S0142716410000391

Publication date:

2011

Document version

Publisher's PDF, also known as Version of record

Citation for published version (APA):

Poulsen, M. (2011). Do dyslexics have auditory input processing difficulties? Applied Psycholinguistics, 32(02), 245-261. https://doi.org/10.1017/S0142716410000391 


\title{
Do dyslexics have auditory input processing difficulties?
}

\author{
MADS POULSEN \\ University of Copenhagen
}

Received: January 17, 2008

Accepted for publication: July 14, 2009

\section{ADDRESS FOR CORRESPONDENCE}

Mads Poulsen, Department of Nordic Studies and Linguistics, University of Copenhagen, Njalsgade 120, Copenhagen DK-2300, Denmark. E-mail: m.poulsen@hum.ku.dk

\begin{abstract}
Word production difficulties are well documented in dyslexia, whereas the results are mixed for receptive phonological processing. This asymmetry raises the possibility that the core phonological deficit of dyslexia is restricted to output processing stages. The present study investigated whether a group of dyslexics had word level receptive difficulties using an auditory lexical decision task with long words and nonsense words. The dyslexics were slower and less accurate than chronological age controls in an auditory lexical decision task, with disproportionate low performance on nonsense words. The finding suggests that input processing difficulties are associated with the phonological deficit, but that these difficulties may be stronger above the level of phoneme perception.
\end{abstract}

Today there is good evidence for the theory that dyslexia is caused by a deficit in phonological abilities (e.g., Snowling, 2000). The specific nature of the phonological deficit, however, is still unclear. It has been suggested that the deficit is one of indistinct phonological representations (Elbro, 1996; Elbro \& Jensen, 2005; Fowler \& Swainson, 2004), less segmented lexical representation (e.g., Fowler, 1991; Metsala, 1999), or deficient mechanisms for handling output representations (Griffiths \& Snowling, 2001; Hulme \& Snowling, 1992).

This paper addresses the central question: at what stage(s) in processing phonological processing do dyslexics experience difficulties; specifically, whether dyslexics also experience difficulties in input processing stages in addition to production stages. The question arises because, although there have been clear and robust findings of group differences in production-based tasks, results on perception-based tasks have been mixed. I present evidence to suggest that dyslexics do have difficulties in input processing.

\section{PRODUCTION}

It is well documented that dyslexics have difficulties in tasks that require speech production. In picture-naming studies, it has been demonstrated that dyslexics 
perform worse compared to both chronological age (CA) and reading age (RA) controls (for a recent review, see Nation, 2005). Furthermore, it has been argued that the picture-naming difficulties are related to the phonological deficit because they mainly are associated with phonologically complex (i.e., long) words (Nation, Marshal, \& Snowling, 2001; Swan \& Goswami, 1997), and because there is an overrepresentation of phonological errors in the dyslexics' error patterns (Dietrich \& Brady, 2001; Nation et al., 2001; Swan \& Goswami, 1997). In addition, Dietrich and Brady found that dyslexics were more likely than controls to make different naming errors when tested on the same word on two separate occasions, suggesting that the naming difficulty is a result of indistinct phonological representations (Elbro, 1996, 1998) or difficulties with accessing phonological representations (Ramus \& Szenkovits, 2008).

There is also robust evidence that dyslexics have difficulties when having to rapidly and repeatedly name a limited number of known words in the rapid automatized naming (RAN) task (Denckla \& Rudel, 1976). There are indications, however, that this deficit is distinct from the phonological deficit (Clarke, Hulme, \& Snowling, 2005; Manis, Seidenberg, \& Doi, 1999; Wolf et al., 2002). It has been suggested that the RAN task taps the ability to arbitrary links between orthographic symbols and sounds (Manis et al., 1999) or control over reading strategy (Clarke et al., 2005) rather than phonological ability. The proposed difference in causes for picture-naming and RAN deficits would also explain why there appear to be no timing deficit associated with picture naming (Nation et al., 2001; Snowling, van Wagtendonk, \& Stafford, 1988), whereas this is the hallmark of the RAN difficulty.

\section{PERCEPTION}

A number of studies have found that some dyslexics perform worse on phoneme perception tasks such as phoneme discrimination and phoneme identification (Adlard \& Hazan, 1998; Manis et al., 1997; Mody, Studdert-Kennedy, \& Brady, 1997). However, perception deficits in the dyslexic groups appear to affect only a minority (Adlard \& Hazan, 1998; Manis et al., 1997; Ramus et al., 2003). Furthermore, Joanisse, Manis, Keating, and Seidenberg (2000) found that the subgroup with perceptual difficulties also had more pervasive language difficulties. Goswami and collegues (Pasquini, Corriveau, \& Goswami, 2007; Thomson, Ben Fryer, \& Goswami, 2006) have in recent studies found that dyslexics have difficulties on some beat detection measures, but they are still surrounded by some controversy (Rosen, 2003).

The question, then, is, why is it difficult to find robust group differences in perception studies, but relatively easy in production studies? One probable answer is that dyslexia is not caused by a perception deficit. In a review of auditory perceptual difficulties in dyslexia and specific language impairment, Rosen (2003, p. 524) concluded that perceptual difficulties are neither necessary nor sufficient for explaining dyslexia, even though it appears that there is an overrepresentation of individuals with perceptual impairment in these populations (cf. also Bailey \& Snowling, 2002). 
However, if we instead ask the question of the input/output asymmetry in an effort to understand the nature of the phonological deficit, for example, which subsystems are affected, a few other possibilities present themselves: (a) the phonological deficit is restricted to output processing systems, (b) the tasks used in previous perception studies have not tapped into the relevant input processing resources, and (c) the tasks used in previous studies of perception have not been sufficiently sensitive. I will discuss these three possibilities in turn.

Poor production performance has been linked to the phonological deficit through the rationale that poor representations explain inaccurate and/or slow performance on tasks that utilize the representations, for example, speech production tasks. The simplest assumption would be that there is a shared set of phonological representations between input and output processing, and according to this assumption we would expect dyslexics to have difficulties with input tasks as well as output tasks. However, this is not what we clearly find in the dyslexia literature.

In the aphasia literature, however, it has been suggested that there are separate input and output phonological representations (e.g., Nickels \& Howard, 1995) or that there are separate access procedures (Hillis, 2001), and it is thus possible that the input/output asymmetry in the literature on dyslexia reflects a selective deficit in either output processing representations or the output processing systems that access the representations (Griffiths \& Snowling, 2001; Hulme \& Snowling, 1992).

However, there is also work in the aphasia literature suggesting that the phoneme identification and discrimination tasks that have been used in the dyslexia literature do not assess all phonological input processes. There are cases of patients without identification or discrimination problems, but who have difficulties rejecting nonsense words in lexical decision tasks (Martin \& Saffran, 2002; Martin, Breedin, \& Damian, 1999). Martin and Saffran (2002) furthermore found that in a group of aphasics, nonsense word performance correlated with the number of phonological picture-naming errors, and that the one patient who had a picture-naming deficit but no difficulty with phoneme identification/discrimination, actually did make a high proportion of nonsense word errors on the lexical decision task. Saffran and Martin argued that whereas word errors can occur as a result of either phonological or semantic disturbances, nonsense word errors occur mainly as a result of disturbances in phonological processing. The rationale is that weak phonological representations makes it more difficult to differentiate a nonsense word from neighboring real words and thus to reject the nonsense word (cf. Constable, Stackhouse, \& Wells, 1997). Weak representation could in principle also result in errors on real words through insufficient activation of lexical representations, but this would probably entail more widespread difficulties in general on receptive vocabulary tasks, of which there is limited evidence in dyslexia (e.g., Swan \& Goswami, 1997). To the extent that the weak representations simply translate into more accepting behavior on the lexical decision task, there should be little or less impact on real word performance. Errors on real words could, however, also stem from plain lack of vocabulary or from insufficient feedback activation from weak semantic representations (Martin \& Saffran, 2002). According to this analysis of the lexical decision task, nonsense word performance is the cleaner and more relevant measure of phonological processing. It is thus possible that there 
are disturbances somewhere in the process that maps phonemic representations to the phonological representations of words, and that the reason why phonological deficits have been better documented in output processing studies of dyslexia is that most of the input studies have used tasks that do not tap the relevant phonological processing resources.

There are a few dyslexia studies that have used lexical decision tasks. Nicolson and Fawcett (1994) found no differences in accuracy between dyslexic and control groups, but they did find that dyslexics were slower than CA controls, whereas the results of the RA comparisons were somewhat unclear. The exact interpretation is complicated, however, because the dyslexics were slower than the controls on other nonphonological reaction time (RT) measures. Contrary to Nicolson and Fawcett, Snowling, Goulandris, Bowlby, and Howell (1986) found that dyslexics were less accurate than CA controls (but as accurate as RA controls) in accepting words, but they did not report nonsense word performance. Using a task similar to lexical decision Fowler and Swainson (2004) found that poor readers were more tolerant than good readers when judging the acceptability of deviant pronunciations of long words. Carroll and Snowling (2004) have similarly presented results indicating that children at risk for dyslexia were worse at detecting word mispronunciations. In the present paper I provide further data on the lexical decision performance of dyslexics.

Other studies have investigated word-level input processing. Desroches, Joanisse, and Robertson (2006) conducted an eye-tracking study where children were instructed to look at one of four items in a computer display. Analyses of the eye-movement data revealed that the control children were momentarily distracted by the existence of pictures with either the same rhyme as the target picture or the same beginning phonemes. Dyslexic children identified the target pictures and were, just as controls, distracted by words with the same beginnings, but they were not distracted by the words with the same rhyme as the target. This suggests that they did not have difficulties with phoneme perception as such, but that there was problem at a higher level of sound representation that also influenced the perception of words. Elbro, Nielsen, and Petersen (1994) reported that after semantic vocabulary was taken into account, adult dyslexics performed worse than controls on a task where participants had to pick the synonym of a test word out of three spoken, phonologically similar words. Again this indicates that dyslexics have word-level input processing difficulties, a notion that is further supported by some studies showing that dyslexics need more material to identify words in gating task compared to age controls (Bruno et al., 2007; Metsala, 1997), but not all results have been positive (Griffiths \& Snowling, 2001).

Looking across these different word-level input studies the results are somewhat mixed, in part because there has been no positive results in RA comparisons. However, compared to the results of the identification/discrimination studies, the results are more suggestive of a phonological deficit shared between the input and the output systems.

It is worth noting that most of the input studies described here have used short stimuli items, whereas many of the production studies have either used only long words (Dietrich \& Brady, 2001) or have found the clear group differences on long words (Nation et al., 2001; Swan \& Goswami, 1997). RAN studies are obvious 
contradictions to this trend, but as mentioned above, there is growing evidence that RAN difficulties are associated with other deficits instead of or in addition to a phonological deficit. That long stimuli appear to be more likely to produce group differences in output studies raises the possibility that previous input studies have not used sufficiently sensitive stimuli to produce group differences (for similar discussion in relation to naming studies, see Swan \& Goswami, 1997). Sensitivity is also relevant to consider in relation to the nature of the tasks used when testing and comparing input and output processing. In most, if not all, output tasks, informants have to produce the entire response from scratch, that is, access the right word representation, make a fully specified articulatory plan, and follow through with the plan under the constraint of time and memory limitations. Most, if not all, input tasks, in contrast, are forced choice tasks, where the opportunity for error is much lower. This task asymmetry makes simple comparisons between input and output tasks difficult (cf. Allport, 1984; Martin \& Saffran, 2002).

In sum, it is possible that dyslexia is associated with input processing difficulties, but that the mixed results are because of the possibility that (a) phoneme discrimination and identification tasks do not test the relevant stage in processing; (b) previous lexical decision studies have not focused on the right data, that is, nonsense word performance; and (c) previous lexical decision studies have not used the most sensitive stimuli, that is, long words, a problem that is accentuated because input tasks, due to their forced choice nature, are less sensitive than open ended output tasks.

There are two research questions for the present paper. (a) Are dyslexics slower and less accurate than controls when judging nonsense words in lexical decision? (b) Does performance on nonsense words in lexical decision correlate with performance on phonological output tasks such as phoneme awareness and nonsense word reading? The first question deals with some of the shortcomings of the possible lack of sensitivity in previous lexical decision designs by using more sensitive materials and RT measures in a RA-match design. The second question deals with validation of the lexical decision task as a measure of those phonological processes relevant for dyslexia. If the ability to reject deviant pronunciations is contingent on phonological representations or processes that are shared between input and output systems, performance on such tasks should correlate with output tasks that are assumed to rely upon the same processes and systems.

\section{METHOD}

\section{Participants}

The dyslexic children were recruited from five schools with special reading programs for Grades 5 and 6 in the Copenhagen area. Only children who were native speakers of Danish with no reported overt general learning or behavioral problems were selected. The test is not normed beyond Grade 3, but a few of the children turned out to score above the 25th percentile for their grade level on the OS-400 Word Decoding Test (Søegård \& Petersen, 1974) used for RA matching (see below for details) based on the scores in the CA screening sample. These children were excluded from all the following analyses because of the suspicion 


\begin{tabular}{|c|c|c|c|c|c|c|c|c|c|}
\hline & \multicolumn{3}{|c|}{ Dyslexics $(N=19)$} & \multicolumn{3}{|c|}{ CA Controls $(N=20)$} & \multicolumn{3}{|c|}{ RA Controls $(N=14)$} \\
\hline & Mean & $S D$ & Range & Mean & $S D$ & Range & Mean & $S D$ & Range \\
\hline Age (months) & 149.3 & 9 & $135-164$ & 149.4 & 9 & $134-163$ & 110.6 & 6 & $101-122$ \\
\hline Reading score ${ }^{a}$ & 67.5 & 28 & $20-98$ & 155.8 & 31 & $101-207$ & 66 & 23 & $30-105$ \\
\hline \multicolumn{10}{|l|}{ Receptive } \\
\hline vocabulary $^{b}$ & 93.6 & 8 & $82-109$ & 94.9 & 11 & $80-117$ & 78.6 & 10 & $65-93$ \\
\hline
\end{tabular}

${ }^{a}$ Number of correct answers within 5 min on the OS400 silent word decoding test.

${ }^{b}$ Number of correct answers on the Danish translation of the Peabody Picture Vocabulary Test.

that they had been referred to reading programs because of other concerns than a specific reading impairment. RA and CA controls were selected from second to third grade and fifth to sixth grade at some of the same schools based on screening using the OS-400 test. Children in the control groups that read below the 25th percentile in their grade group were excluded out of a concern that they might have had undiagnosed learning disabilities. For the RA control group, children were chosen to match the dyslexic group on mean reading. A balancing issue in the lexical decision experiment made it necessary to remove four dyslexics and six RA controls from the sample. These were chosen on the basis of silent decoding and receptive vocabulary score such that reading level match and vocabulary match between the dyslexics and CA controls was upheld, but without looking at data from the other experiments (Table 1).

\section{Tests and materials}

Except for the silent word decoding test used for RA matching, the children were tested individually in quiet rooms at the schools over two sessions lasting 30-45 min, each on separate days. Each session consisted of a number of tests that were administered in the same order for every child. Some of the tests were carried out on a Thinkpad laptop with an attached serial response box using the E-prime experimental software. The tests are described in the order of administration in the following.

Silent word decoding. The paper based OS-400 test (Søegård \& Petersen, 1974) was used for RA matching. It was administered on a group basis. The test consists of 400 isolated test items. For each item the participants had to select which of four pictures matches a written word. Items were presented in rows in a booklet, and the participants were instructed to complete as many as possible within a time limit. The score was computed as the number of correct responses made within a 5-min time limit. Test-retest correlation has previously been reported at 0.93 (Elbro, Rasmussen, \& Spelling, 1996). 
General RT. In this computer-based task, the children saw three symbols lined up vertically on the screen: two asterisks and a plus sign. The goal was to determine as quickly as possible where the plus sign was, and push one of three buttons on the button box corresponding to the spatial position on the screen.

Lexical decision. In the computer-based lexical decision task, the children were asked to decide whether spoken words were real words or nonsense words. They were told to be careful because the nonsense words sounded very similar to real words, but also that they should decide fast. The test started with 10 practice items illustrating that the nonsense words closely resembled real words. Children scoring below $80 \%$ correct on the practice items were given new rounds of practice until they met the $80 \%$ criterion.

Materials for the experiment consisted of 56 words and 56 nonwords. The words were three to five syllables long, and pronounced distinctly. To make the stimuli maximally sensitive, nonsense words were derived from words by changing a weak vowel for another full vowel, while keeping the stress patterns unchanged. For example, $t^{s}$ elə'fo? $n$ ("telephone") was changed to $t^{s}$ ela'fo? $n$ (vowel reduction in unstressed syllables is not obligatory in Danish, especially not in distinct pronunciation). A weak vowel was defined as schwa or a vowel that routinely is reduced to schwa or completely omitted (see Appendix A for a full list of items). Weak vowels were determined using a dictionary of pronunciation (Brink, Heger, \& Lund, 1991) and judgments made by the author and a trained phonetician. The rationale was that if dyslexics have poor-quality representations, weak vowels would constitute the least stable parts of the representations because a person will be subjected to much variation in these segments in their listening experience.

Average duration of words and nonsense words were 637 and $642 \mathrm{~ms}$, respectively. This difference was not significant $(F=0.11)$. Two counter balanced lists with 26 words and 26 nonsense words each were created. A list only contained one of a word-nonsense word pair. Each list was seen by an equal number of participants from each group. Items were read aloud with distinct pronunciation by a male speaker and recorded in a sound studio. Recordings were digitized at a $44.1-\mathrm{kHz}$ sampling rate using Praat. Sounds were played at a comfortable listening level through headphones. The children made decisions by pressing one (right) button for word and another (left) button for nonsense word. RT from the beginning of a stimuli presentation was recorded along with accuracy.

Receptive vocabulary. Raw score (number of correct answers) on a Danish translation of the Peabody Picture Vocabulary Test (Dunn \& Dunn, 1981) was used to assess receptive vocabulary. The Danish version has been used for research previously (Elbro, Borstrøm, \& Petersen, 1998), but has not been standardized.

Nonsense and irregular word reading. Participants had to read out loud 20 irregular words followed by 40 nonsense words. Items were printed on three separate sheets with 20 items on each. Irregular words were taken from Elbro (1990). The nonsense words were from Elbro (1990) and Elbro et al. (1994). In both tasks the items were between two and nine characters long, and generally increased in difficulty through each sheet. The nonwords were phonotactically legal. The 
Table 2. Summary of data from phoneme deletion, reading aloud, and reaction time

\begin{tabular}{|c|c|c|c|c|c|c|}
\hline & \multicolumn{2}{|c|}{$\begin{array}{l}\text { Dyslexics } \\
(n=19)\end{array}$} & \multicolumn{2}{|c|}{$\begin{array}{l}\text { CA Controls } \\
(n=20)\end{array}$} & \multicolumn{2}{|c|}{$\begin{array}{l}\text { RA Controls } \\
\quad(n=14)\end{array}$} \\
\hline & Mean & $S D$ & Mean & $S D$ & Mean & $S D$ \\
\hline deletion (max 3 & 15.00 & 10.17 & 25.90 & 1.97 & 17.86 & $7-71$ \\
\hline Nonsense word reading & 19.58 & 11.15 & 35.35 & 6.73 & 29.00 & 7.59 \\
\hline Irregular word reading & 5.37 & 3.85 & 18.35 & 2.76 & 7.79 & 3.85 \\
\hline General reaction accuracy & 0.95 & 0.05 & 0.97 & 0.05 & 0.96 & 0.03 \\
\hline General reaction time $(\mathrm{ms})$ & 549.72 & 79.31 & 489.23 & 53.07 & 752.03 & 154.52 \\
\hline
\end{tabular}

Note: CA, chronological age; RA, reading age.

irregular words were mostly frequent words. The participants were asked to read the items one at a time without going back, and to take the time they needed. The score for each task was the total number of correctly read items.

Phoneme deletion. This phonemic awareness task was adapted for computer administration from Arnbak and Borstrøm (2007). It consisted of two separate subsections. In both sections the participants had to listen to a word, remove a specific sound from the word, and say out loud the resulting word, for example, what is left if you remove / $k$ / from kost ("broom"). Answer: ost ("cheese"). In the first section, only the first phonemes were to be deleted (10 items). In the second section medial and final phonemes are to be deleted (20 items alternating between medial and final deletion). Test items were recorded using a male speaker. A section was terminated if a participant made four errors in a row. The score was the total number of correctly produced words across the two sections. The correlation between the first and second section was at .75.

\section{RESULTS}

\section{Phoneme awareness, reading aloud, and general RT}

Summary data from reading aloud, phoneme awareness and general RT tasks can be found in Table 2 .

The CA controls outperformed dyslexics on all tasks (all $F \mathrm{~s}>16$ ). There was no difference between dyslexics and RA controls on phoneme deletion $(F<1)$, a marginal difference on irregular word reading, $F(1,32)=3.18, p=.08$, and the RA controls outperformed the dyslexics on nonsense word reading $F(1,32)=$ $7.43, p<.05)$. These results confirm that the dyslexic group was reading impaired not only in terms of fluency as measured by the OS-400 Silent Decoding Test but also in terms of reading precision, and more so on nonword reading than irregular word reading. In the phoneme deletion task, $74 \%$ of the dyslexics performed below $1 S D$ of the CA group mean, $100 \%$ fell below in irregular word reading and $74 \%$ fell below in nonsense word reading. On the measure of general RT, 


\begin{tabular}{|c|c|c|c|c|}
\hline & \multicolumn{2}{|c|}{ Words } & \multicolumn{2}{|c|}{ Nonsense Words } \\
\hline & Mean & $S D$ & Mean & $S D$ \\
\hline \multicolumn{5}{|l|}{ Dyslexics $(N=19)$} \\
\hline Accuracy (proportion correct) & 0.84 & 0.10 & 0.73 & 0.14 \\
\hline $\mathrm{RT}(\mathrm{ms})$ & 1077.28 & 124.83 & 1149.32 & 122.04 \\
\hline \multicolumn{5}{|l|}{ CA controls $(N=20)$} \\
\hline Accuracy (proportion correct) & 0.89 & 0.07 & 0.87 & 0.09 \\
\hline $\mathrm{RT}(\mathrm{ms})$ & 1060.27 & 193.66 & 1049.63 & 128.39 \\
\hline \multicolumn{5}{|l|}{ RA controls $(N=14)$} \\
\hline Accuracy (proportion correct) & 0.81 & 0.12 & 0.72 & 0.16 \\
\hline $\mathrm{RT}(\mathrm{ms})$ & 1315.42 & 126.05 & 1390.48 & 144.47 \\
\hline
\end{tabular}

Note: RT, reaction time; $\mathrm{CA}$, chronological age; RA, reading age.

CA controls outperformed the dyslexics, $F(1,37)=7.91, p<.01$, and the dyslexics outperformed the RA controls, $F(1,31)=24.14, p<.001$. There was no difference in accuracy in any of the comparisons on this measure.

\section{Lexical decision}

I present separate analyses of accuracy and RT for the comparison between dyslexics and CA age controls on the one hand, and the dyslexics and RA controls on the other. Analyses of accuracy were performed on percentage of correct answers. All children except one from the younger group answered above chance level of $60 \%$. In analyses of RT, only RTs from correct responses were used, and for each subject RTs above or below $2 S D$ of the subjects mean for a certain condition were left out of the analysis. This affected less than $5 \%$ of the data. The RTs were then log transformed to normalize distributions for use in the following analyses of variance (ANOVAs; Table 3).

Dyslexics and CA controls. The accuracy data were subjected to a 2 (Group) $\times 2$ (Condition) ANOVA with repeated measures on the condition factor. There were main effects of group, $F(1,37)=13.3, p<.001$, and condition, $F(1,37)=$ $8.44, p<.01$. The interaction was marginally significant, $F(1,37)=3.81, p=$ $.06{ }^{1}$ Tests of simple main effects showed that the dyslexics were marginally less accurate on words, $F(1,37)=2.98, p=.09$, but significantly less accurate on nonsense words, $F(1,37)=12.48, p=.001$.

A similar analysis was performed on the RT data. There was a marginally significant main effect of condition, $F(1,37)=3.59, p=.07$, but no effect of group, $F(1,37)=2.32, p=.14$. The interaction was, however, significant, $F(1$, $37)=4.28, p<.05$.

Tests of simple effects showed that dyslexics were reliably slower on nonsense words, $F(1,37)=6.16, p<.05$, but not on words $(F<0.2)$. 
To sum up, the dyslexics had clear difficulties with rejecting the nonsense words, whereas the group differences are less clear on word performance. As a measure of how widespread deviant performance in the dyslexia group was, $63 \%$ of the dyslexics scored below $1 S D$ of the CA group mean in nonsense word accuracy, compared to $15 \%$ in the CA group.

Dyslexics and RA controls. ANOVAs of the accuracy data with group and condition as factors only revealed a main effect of condition, $F(1,31)=9.26, p<.01$ (all other $F \mathrm{~s}<1$ ). In the RT analysis, there were main effects of group, $F(1,31)=$ $35.16, p<.001$, and condition, $F(1,31)=17.52, p=.001$. The dyslexics were faster than the RA controls. There was no interaction $(F \mathrm{~s}<1)$. In sum dyslexics were faster than RA controls, and words were responded to faster and with greater accuracy than nonsense words.

Because the groups differed in general RT performance, all RT ANOVAs were rerun with the residuals of regressions of general RT on lexical decision RT. This removed the main effect of group in the RA comparison, $F(1,31)=2.76$, $p=.11$, but the remaining conclusions remain the same. In other words, when general RT is taken into account, the dyslexics seemed to perform like the RA controls.

\section{Correlations}

Table 4 shows correlations between nonword performance, phonemic awareness, nonsense word, and irregular word reading, and general RT computed separately for each group.

The hypothesis was that if lexical decision is a measure of phonological processing, lexical decision performance should correlate with other traditional measures of phonological processing, specifically phonemic awareness and nonsense word reading. Such correlations were only reliably found in the CA group, where lexical decision accuracy on nonsense word accounted for $22 \%$ of the variance in phonemic awareness and $20 \%$ of the variance in nonsense word reading. In the RA group, lexical decision accuracy also accounted for $22 \%$ of the variance in phonemic awareness, but this was not significant because of the smaller sample size.

The correlation analyses did reveal one unexpected pattern with regard to the relationship between speed and accuracy in the lexical decision data. In the CA control group there was a tendency for accuracy being positively correlated with speed $(r=.42, p=.08)$ such that the individuals who spent more time on this task were more accurate. The trend was the opposite for the dyslexia group where the individuals who spent most time on nonsense words were the ones who scored the lowest $(r=-.59, p<.05)$. There was no significant trend in the RA control group. A possible explanation for this pattern might be that there is a normal speed accuracy trade-off in the CA control group, such that spending more time on the task yields better performance, whereas the slowest performers in the dyslexia group are slow because they find the task very difficult. This finding suggests that the dyslexics process this task differently from the other groups. 
Table 4. Simple correlations between key measures

\begin{tabular}{|c|c|c|c|c|c|c|}
\hline Dyslexics & 1 & 2 & 3 & 4 & 5 & 6 \\
\hline 1. LD-nonword accuracy & 1 & & & & & \\
\hline 2. LD-nonword RT & $-.586^{* *}$ & 1 & & & & \\
\hline 3. Phonemic awareness & .298 & -.001 & 1 & & & \\
\hline 4. Nonsense word reading & .175 & .165 & $.912 * * *$ & 1 & & \\
\hline 5. Irregular reading & 146 & -.155 & $.704 * * *$ & $.791 * * *$ & 1 & \\
\hline 6. General RT & $-.500 * *$ & $.678 * *$ & .107 & .230 & .043 & 1 \\
\hline CA Controls & 1 & 2 & 3 & 4 & 5 & 6 \\
\hline 1. LD-nonword accuracy & 1 & & & & & \\
\hline 2. LD-nonword RT & .422 & 1 & & & & \\
\hline 3. Phonemic awareness & $.472 *$ & .013 & 1 & & & \\
\hline 4. Nonsense word reading & $.453 *$ & -.097 & .423 & 1 & & \\
\hline 5. Irregular reading & .166 & -.287 & .375 & $.699 * * *$ & 1 & \\
\hline 6. General RT & .238 & $.559 *$ & .139 & -.267 & $-.501 *$ & 1 \\
\hline RA Controls & 1 & 2 & 3 & 4 & 5 & 6 \\
\hline 1. LD-nonword accuracy & 1 & & & & & \\
\hline 2. LD-nonword RT & .216 & 1 & & & & \\
\hline 3. Phonemic awareness & .472 & .453 & 1 & & & \\
\hline 4. Nonsense word reading & .233 & .223 & $.744 * *$ & 1 & & \\
\hline 5. Irregular reading & .208 & -.054 & .530 & $.720 * *$ & 1 & \\
\hline 6. General RT & -.120 & -.136 & -.377 & -.195 & -.455 & 1 \\
\hline
\end{tabular}

Note: LD, lexical decision, RT, reaction time; CA, chronological age; RA, reading age. $* p<.05 . * * p<.01 . * * * p<.001$.

\section{GENERAL DISCUSSION}

The central aim of the present study was to find out whether dyslexics have wordlevel difficulties with auditory input processing. This turned out to be the case. The dyslexics performed less accurately than chronological controls on a lexical decision task with long stimuli, and the difference was disproportionally large with regard to the ability to reject nonsense words. Furthermore, the dyslexics were slower to reject nonsense words, even when they did answer correctly. These results indicate that the dyslexics may have an input processing difficulty. The implication is that the cognitive disturbances associated with dyslexia are not restricted to output processing as has been suggested (Griffiths \& Snowling, 2001; Hulme \& Snowling, 1992). The results complement previous studies demonstrating dyslexics' age-related deficits in input processing that supposedly depend on high-level representations (Desroches et al., 2006; Elbro et al., 1994). These results and the more mixed results on phoneme-level tasks in the literature (Adlard \& Hazan, 1998; Landerl \& Wimmer, 2000; Manis et al., 1997; Ramus et al., 2003) are suggestive of a word-level deficit in the quality of phonological representations (Elbro, 1996; Fowler \& Swainson, 2004) shared between input and output processing. A different possibility is that the representational deficit is at a 
sublexical level, but in such a way that phoneme perception is relatively intact. Finally, the result pattern may also be compatible with a theory that explains deficits in input and output performance in terms of a deficit in phonological memory or access to phonological representations (Ramus \& Szenkovits, 2008), for example, because of rapid decay at phoneme level (e.g., Martin et al., 1999). It should be noted that these different possibilities are not mutually exclusive. For example, a phonological memory problem would probably lead to impaired sublexical and lexical representations, and impaired lexical representation would provide less support for establishing memory efficient sublexical representations. Dyslexics have been shown to have difficulties with repeating nonsense words (Snowling et al., 1986; Stone \& Brady, 1995), and this has been interpreted to show that the problem resides at the sublexical level (Szenkovits \& Ramus, 2005). However, dyslexics have also been shown to have difficulties with learning new word forms despite having good immediate recall of the forms (Mayringer \& Wimmer, 2000). This has been interpreted to show that the problem rather is of establishing precise lexical representations. The present results do not allow us to choose between these interpretations, and because establishing word representation presumably draws on sublexical skills, it is a big challenge to figure out ways to tease these issues apart. The goal of the present study was, however, simply to establish whether dyslexia is associated with an input processing problem.

Given the recent controversy on the existence of auditory rise-time perception deficits in dyslexia (Pasquini et al., 2007; Richardson, Thomson, Scott, \& Goswami, 2004; Rosen, 2003), it should be noted the present results are probably only loosely related to this issue. Such a deficit has been suggested as the cause of poor phonological representations, and as such is compatible with the present results. However, it is doubtful whether a rise-time perception deficit could be the immediate cause of the present lexical decision result pattern, and the present results do not rule out such a deficit.

The present experiments also demonstrated a group difference between the dyslexics and the CA controls in the nonlinguistic RT task. This could be interpreted as deficit in stimulus classification speed (Nicolson \& Fawcett, 1994), but another possible interpretation is the difference arises from differences in approach to being tested. The dyslexics were used to being tested on tasks that they find very difficult (e.g., reading), and this might have made their initial approach more careful than that of their age peers, even on tasks they find easy. As a subjective observation, the dyslexics did seem more anxious than the controls upon starting the test sessions. In anticipation of this, tasks that the dyslexics would know they would have difficulty with (reading, phoneme deletion) were placed last in the test sessions. A possible explanation for the findings that dyslexics were just as fast as the CA controls in accepting real words in the lexical decision task could be that they had they calmed down during the nonlinguistic RT task, which was the first task. Given this possibility we do not want to conclude that the dyslexics had a general RT deficit. In any event, the classification speed hypothesis cannot explain the result that the dyslexics had disproportional difficulties with nonsense words.

The precise interpretation of the lexical decision results as characteristic of a cognitive deficit underlying reading failure is made difficult by two factors, however. First, the dyslexics performed as the RA controls on the lexical decision task, making it impossible to conclude whether the poor performance was 
because of the underlying cognitive cause of dyslexia or to poor reading ability or experience. It is perfectly possible that a stabilization or specification of lexical phonological representations is a side effect of reading experience; robust experience with how weak segments are spelled may help specify the phonological representations of these words. However, neither can we rule out that unstable phonological input processing or representations are an attribute of the cognitive impairment that causes dyslexia. This is a limitation of the RA match design (Bryant \& Goswami, 1986). Notice that there was a similar problem with phoneme awareness in this study, because the expected group difference in RA comparisons on the traditional dyslexia measures was only obtained reliably in the nonsense word-reading task. Because there were age-related differences in both vocabulary and general RT further highlights the problem of the RA comparison: even though the dyslexic and the RA control group were matched on reading level, the dyslexics had additional age related nonphonological resources that they could potentially draw on in solving a task, and this could hide actual differences in the ability that a given task is designed to measure. One way to progress beyond the limitation in the RA match design is to investigate how lexical decision performance predicts reading ability in longitudinal designs.

Second, the other problem of interpretation stems from the lack of clear correlations between lexical decision performance and the traditional phonological measures of phoneme awareness and nonsense word reading. The lack of correlation could be taken as an indication of the lack of validity of lexical decision performance as indexing phonological processing, or that it indexes another kind of phonological processing.

Yet another possible explanation for the unclear correlation between lexical decision and traditional phonological measures is that the shared phonological component between the tasks is washed out by differences in task demands. Nonsense word reading is obviously contingent upon reading ability in addition to phonological processing. The phoneme deletion task is quite complex in that it, in addition to phonological resources, depends on the ability to perform two distinct operations (identifying a specific segment, deleting the segment) on a representation held in working memory (Yopp, 1988), and phoneme awareness tasks have been shown not to correlate with other phonological tasks once reading ability is taken into account (Foy \& Mann, 2001). In this light, lexical decision appears to be a more "clean" task, primarily requiring a match between an auditory input and a word representation. However, it is obvious that more research is needed to establish the validity of this task as a measure of phonological distinctness.

The present data do not allow us to differentiate between these possibilities, but validation of lexical decision as a phonological measure and the factoring out of the phonological components of nonsense word reading and phoneme awareness tasks are both good subjects for further research. If it turns out that phoneme awareness does rely heavily on nonphonological skills, such as the ability to attend to and manipulate representations held in working memory, and these skills are important for reading acquisition, then this would explain why performance on phoneme awareness tasks are such good predictors of reading development (Scarborough, 1998); by being dependent on several component abilities of reading, a task will have a better chance of detecting weaknesses that may lead to reading failure than tasks that only test one subcomponent. The price of measures that aggregates 
Poulsen: Input processing in dyslexia

different abilities is that they contribute less to our understanding of the precise nature of the problem.

Lexical decision measures are not going to replace phoneme awareness or nonsense word reading as a diagnostic of dyslexia, but they may provide insight into the nature of the cognitive problems that are the source of reading disability.

\section{APPENDIX A}

Table A.1 provides the 56 items in the auditory lexical decision task. Each item consists of a word and a derived nonsense word. Each participant saw only the word or the nonsense

Table A.1. Items in the auditory lexical decision task

\begin{tabular}{|c|c|c|c|}
\hline Word & $\begin{array}{l}\text { Nonsense } \\
\text { Word }\end{array}$ & Word & $\begin{array}{l}\text { Nonsense } \\
\text { Word }\end{array}$ \\
\hline 'dog̊əhu's (“doll house”) & 'dog̊ahu?s & $\begin{array}{l}\text { 'bọ:ęnəhæ:və } \\
\text { ("kindergarten”) }\end{array}$ & 'b̋œพ̣nohæ:və \\
\hline 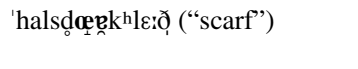 & 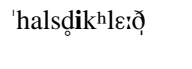 & $\begin{array}{l}\text { ha'mo? nikha } \\
\text { ("harmonica") }\end{array}$ & ho'mo? nikha \\
\hline k ${ }^{\mathrm{h}} \Lambda$ jgu' вађsә (“competition”) & $\mathrm{k}^{\mathrm{h}} \Lambda$ „ga' вауsә & medi'si'n ("medicine") & meda'si ${ }^{?} \mathrm{n}$ \\
\hline sig̊a' ваd̆ (“cigarette") & sig̊o' ваd̆ & 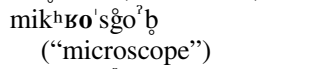 & mik $^{h}$ sa'sg̊o ${ }^{?} b$ \\
\hline 'najləlag̊ ("nail polish”) & 'najlulag̊ & 'nع:səhoe eñ n ("rhinoceros") & 'ne:sihoper ${ }^{2} n$ \\
\hline 'febьима" ("february”) & 'febьвia' & $\begin{array}{l}\text { ba'gaæ:cobc:e } \\
\text { ("luggage carrier") }\end{array}$ & ba'g̊æ:cober: \\
\hline 'gвash^bəo ("locust”) & 'gвash^baa & $\begin{array}{l}\log \mathbf{o m o} \mathrm{t}^{\mathrm{s}} \mathrm{iw}{ }^{3} \\
\text { ("locomotive") }\end{array}$ & $\log i m o ' t^{S} i w^{2}$ \\
\hline heli'kh $\Lambda$ bdo & hela'k $\mathrm{k}^{\mathrm{h}} \Lambda \mathrm{b} d \mathrm{~d} \mathrm{e}$ & 'guləвœðе (“carrots”) & 'gulaвœðе \\
\hline khasə'в цlə (“pot") & 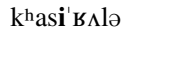 & $\begin{array}{l}\text { sent }{ }^{\mathrm{S}} \mathbf{i}^{\prime} \mathrm{i}^{\mathrm{P}} \mathrm{de} \\
\text { ("centimeter") }\end{array}$ & $\operatorname{sent}{ }^{\mathrm{S}} \mathbf{o} \mathrm{me}^{?} \mathrm{de}$ \\
\hline 'sleg̊əphen? (“lollipop”) & 'sleg̊aphen' & hosbi't $\mathrm{t}^{\mathrm{s}} \mathfrak{x}^{\mathrm{T}} 1$ ("hospital") & hosbu't $t^{S} \mathfrak{x}^{?} 1$ \\
\hline $\mathrm{k}^{\mathrm{h}} \Lambda \mathrm{t}^{\mathrm{S}} \mathrm{\partial}^{\prime} \mathrm{l}_{\mathrm{o}}^{\mathrm{d}}$ ("chop") & $\mathrm{k}^{\mathrm{h}} \Lambda \mathrm{t}^{\mathrm{s}} \mathbf{i}^{\prime} \mathrm{l}_{0} \mathrm{~d}$ & вæsdос' ваך ("restaurant") & вæsd̋' ваך \\
\hline 'phublik'om ("audience") & 'phublakhom & manda' si $^{?}$ n ("tangerine") & $\operatorname{mand} \mathbf{y}^{\prime}$ ві ${ }^{?} \mathrm{n}$ \\
\hline gøクəsda'tiw? (“swing set”) & gønisda'tiw ${ }^{?}$ & 'cibəot' $\Lambda \mathrm{W}$ (“jump rope”) & 'cibot ${ }^{\mathrm{s}} \Lambda \mathrm{W}$ \\
\hline pheli'khæ'n ("pelican") & $\mathrm{p}^{\mathrm{h}} \mathrm{el} \mathbf{u}^{\prime} \mathrm{k}^{\mathrm{h}} \mathfrak{x}^{?} \mathrm{n}$ & $t^{\mathrm{S}}$ elə'fo? $\mathrm{n}$ ("telephone") & $t^{S}$ ela for $n$ \\
\hline 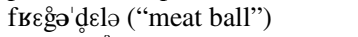 & 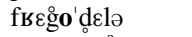 & phabə'g̊ $\Lambda$ jj ("parrot") & $\mathrm{p}^{\mathrm{h}} \mathrm{ab} \mathbf{o}^{\prime} \mathrm{g}_{\Lambda} \mathrm{jj}$ \\
\hline 'homləbi ("bee") & 'homlabi i & ambu'lajsə ("ambulance") & amba'lajsə \\
\hline عg̊ddə'sg̊ææ bo ("marriage") & 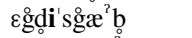 & mağa' ві:nә ("margarine”) & mağo' ві:nә \\
\hline 'vanmelo?n ("watermelon") & vanmulo? $\mathrm{n}$ & $\begin{array}{l}\text { t' }{ }^{\mathrm{S}} \text { ваmbo'li" } \mathrm{n} \\
\text { ("trampoline") }\end{array}$ & tвamba'li ${ }^{?} n$ \\
\hline 'khø:lesgæb ("refrigerator") & 'khø:lusgæb & $\begin{array}{l}\text { 'vasg̊əmasg̊inə } \\
\text { ("washing machine") }\end{array}$ & 'vasg̊umasg̊iñ \\
\hline kh'Bog̊o'dilə (“crocodile") & $\mathrm{k}^{\mathrm{h}}$ Bog̊a'dilə & 'melg̊əbødٍ (“dandelion”) & 'melg̊abødo \\
\hline $\begin{array}{l}\mathrm{t}^{\mathrm{S}} \varepsilon \text { mbəва }^{\prime} \mathrm{t}^{\mathrm{s}} \mathrm{u}^{2} \mathrm{v} \\
\text { ("temperature") }\end{array}$ & $\mathrm{t}^{\mathrm{S}} \varepsilon$ mbi isa'tu ${ }^{?} \mathrm{r}$ & sba'g̊gdi ("spaghetti”) & sbu'g gedi \\
\hline elə'væ:t ${ }^{\mathrm{s}} \mathrm{p}$ ("elevator") & elo'væ: $t^{\mathrm{S}} \mathrm{D}$ & 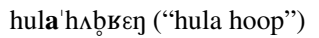 & huli'h $\Lambda$ bo $\varepsilon \varepsilon \eta$ \\
\hline $\begin{array}{l}\text { eleğt }{ }^{\mathrm{S}} \text { bisi' } \mathrm{t}^{\mathrm{S}} \mathrm{e}^{\mathrm{T}} \mathrm{d} \\
\text { ("electricity") }\end{array}$ & eleğt ${ }^{\mathrm{S}}$ вisu't ${ }^{\mathrm{S}} \mathrm{e}^{?}{ }_{0}^{\mathrm{d}}$ & 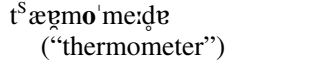 & $\mathrm{t}^{\mathrm{s}}$ æe્nma'me:dẹ \\
\hline fot $^{\mathrm{s}}$ оğва'fi ("photography") & fot $^{\mathrm{S}} \mathbf{i g}_{\mathrm{g}} \mathrm{s} \mathrm{fi}^{?}$ & 'asg̊obere ("ash tray") & 'asg̊obe:r \\
\hline phy'jæ:mas ("pajamas") & $\mathrm{p}^{\text {h}} \mathbf{u}^{\prime}$ jæ:mas & elə'fan'do ("elephant") & elu'fan ${ }^{2} \mathrm{~d}$ \\
\hline 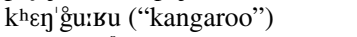 & kºך’g̊gu:su & cog̊o'læ:ðə (“chokolade”) & cog̊i'læ:ðə \\
\hline 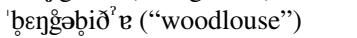 & 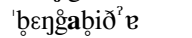 & biblio'te ${ }^{?} \mathrm{~g}$ ("library") & biblao ${ }^{\prime} t^{S} e^{?} g$ \\
\hline gymna'sdig ("gymnastics") & gymmi'sdig & 'khæ? тәка ("camera") & 'khæ това \\
\hline
\end{tabular}


word of a specific item. Weak vowels are indicated in bold. The items are transcribed in a version of the IPA font that is slightly accommodated to Danish (Grønnum, 2000).

\section{ACKNOWLEDGMENTS}

This work was made possible by a grant from the Danish Research Council for the Humanities awarded to the author. The paper has benefited greatly from discussions with Carsten Elbro, Holger Juul, and Nicolai Pharao. I am greatly indebted to the children and teachers who volunteered to participate in this work.

\section{NOTE}

1. A reviewer pointed out that it is a problem that there was no verification that the students knew the words used in the experiment. Three words were incorrectly rejected more than $40 \%$ of the time: helikopter ("helicopter"), krokodille ("crocodile"), and kotelet ("chop"), leaving the possibility that these words were not known to the students. Two of these words, however, were part of a task from a different study where the students under time pressure had to point out the picture corresponding to a spoken word. All the dyslexics pointed out "helicopter" correctly, and all except one pointed out "crocodile" correctly. Leaving these items out of the analyses did not change the effects substantially.

\section{REFERENCES}

Adlard, A., \& Hazan, V. (1998). Speech perception in children with specific reading dificulties (dyslexia). Quarterly Journal of Experimental Psychology, 51A, 153-177.

Allport, A. (1984). Speech production and comprehension: One lexicon or two? In Cognition and motor processes (pp. 209-228). Berlin: Springer-Verlag.

Arnbak, E., \& Borstrøm, I. (2007). Udvikling og afprøvning af procedure til identifikation af elever i risikogruppe for dysleksi. In B. D. Jandorf (Ed.), Vard at vide om ordblindhed (pp. 1-40). Lyngby, Denmark: Dansk Videnscenter for Ordblindhed.

Bailey, P. J., \& Snowling, M. J. (2002). Auditory processing and the development of language and literacy. Britsh Medical Bulletin, 63, 135-146.

Brink, L., Heger, S., \& Lund, J. (1991). Den store danske udtaleordbog. København: Munksgaard.

Bruno, J. L., Manis, F. R., Keating, P., Sperling, A. J., Nakamoto, J., \& Seidenberg, M. S. (2007). Auditory word identification in dyslexic and normally achieving readers. Journal of Experimental Child Psychology, 97, 183-204.

Bryant, P., \& Goswami, U. (1986). Strengths and weaknesses of the reading level design: A comment on Backman, Mamen, and Ferguson. Psychological Bulletin, 100, 101-103.

Carroll, J. M., \& Snowling, M. J. (2004). Language and phonological skills in children at high risk of reading difficulties. Journal of Child Psychology and Psychiatry, 45, 631-640.

Clarke, P., Hulme, C., \& Snowling, M. (2005). Individual differences in RAN and reading: A response timing analysis. Journal of Research in Reading, 28, 73-86.

Constable, A., Stackhouse, J., \& Wells, B. (1997). Developmental word-finding difficulties and phonological processing-The case of the missing handcuffs. Applied Psycholinguistics, 18, 507-536.

Denckla, M. B., \& Rudel, R. G. (1976). Rapid “automatized” naming (R.A.N.): Dyslexia differentiated from other learning disabilities. Neuropsychologia, 14, 471-479.

Desroches, A. S., Joanisse, M. F., \& Robertson, E. K. (2006). Specific phonological impairments in dyslexia revealed by eyetracking. Cognition, 100, B32-B42.

Dietrich, J. A., \& Brady, S. A. (2001). Phonological representations of adult poor readers: An investigation of specificity and stability. Applied Psycholinguistics, 22, 383-418.

Dunn, L. M., \& Dunn, L. M. (1981). Peabody Picture Vocabulary Test-Revised. Circle Pines, MN: American Guidance.

Elbro, C. (1990). Differences in dyslexia. Copenhagen: Munksgaard. 
Poulsen: Input processing in dyslexia

Elbro, C. (1996). Early linguistic ability and reading development: A review and a hypothesis. Reading and Writing: An Interdisciplinary Journal, 8, 453-485.

Elbro, C. (1998). When reading is "readn" or somthn. Distinctness of phonological representations of lexical items in normal and disabled readers. Scandinavian Journal of Psychology, 39, 149-153.

Elbro, C., Borstrøm, I., \& Petersen, D. K. (1998). Predicting dyslexia from kindergarten: The importance of distinctness of phonological representations of lexical items. Reading Research Quarterly, 33, 36-60.

Elbro, C., \& Jensen, M. N. (2005). Quality of phonological representations, verbal learning, and phoneme awareness in dyslexic and normal readers. Scandinavian Journal of Psychology, 46, 375-384.

Elbro, C., Nielsen, I., \& Petersen, D. K. (1994). Dyslexia in adults: Evidence for deficits in nonword reading and in the phonological representation of lexical items. Annals of Dyslexia, 44, 205-224.

Elbro, C., Rasmussen, I., \& Spelling, B. (1996). Teaching reading to disabled readers with language disorders: A controlled evaluation of synthetic speech feedback. Scandinavian Journal of Psychology, 37, 140-155.

Fowler, A. E. (1991). How early phonological development might set the stage for phoneme awreness. In S. Brady \& D. Shankweiler (Eds.), Phonological processes in literacy. Hillsdale, NJ: Erlbaum.

Fowler, A. E., \& Swainson, B. (2004). Relationships of naming skills to reading, memory, and receptive vocabulary: Evidence for imprecise phonological representations of words by poor readers. Annals of Dyslexia, 54, 247-280.

Foy, J. G., \& Mann, V. (2001). Does strength of phonological representations predict phonological awareness in preschool children? Applied Psycholinguistics, 22, 301-325.

Griffiths, Y. M., \& Snowling, M. J. (2001). Auditory word identification and phonological skills in dyslexic and average readers. Applied Psycholinguistics, 22, 419-439.

Grønnum, N. (2000). Danish. Journal of the International Phonetic Association, 28, 99-105.

Hillis, A. E. (2001). The organization of the lexical system. In B. Rapp (Ed.), The handbook of cognitive neuropsychology, What deficits reveal about the human mind. New York: Psychology Press.

Hulme, C., \& Snowling, M. (1992). Deficits in output phonology: An explanation of reading failure? Cognitive Neuropsychology, 9, 47-72.

Joanisse, M. F., Manis, F. R., Keating, P., \& Seidenberg, M. S. (2000). Language deficits in dyslexic children: Speech perception, phonology and morphology. Journal of Experimental Child Psychology, 77, 30-60.

Landerl, K., \& Wimmer, H. (2000). Deficits in phoneme segmentation are not the core problem of dyslexia: Evidence from German and English children. Applied Psycholinguistics, 21, 243262.

Manis, F. R., McBride-Chang, L., Seidenberg, M., Keating, P., Doi, L. M., Munson, B., et al. (1997). Are speech perception deficits associated with developmental dyslexia? Journal of Experimental Child Psychology, 66, 211-235.

Manis, F. R., Seidenberg, M. S., \& Doi, L. M. (1999). See Dick RAN: Rapid naming and the longitudinal prediction of reading subskills in first and second graders. Scientific Studies of Reading, 3, 129157.

Martin, N., \& Saffran, E. M. (2002). The relationship of input and output phonological processing: An evaluation of models and evidence to support them. Aphasiology, 16, 107-150.

Martin, R. C., Breedin, S. D., \& Damian, M. F. (1999). The relation of phoneme discrimination, lexical access, and short-term memory: A case study and interactive activation account. Brain and Language, 70, 437-482.

Mayringer, H., \& Wimmer, H. (2000). Pseudoname learning by German-speaking children with dyslexia: Evidence for a phonological learning deficit. Journal of Experimental Child Psychology, 75, 116-133.

Metsala, J. L. (1997). Spoken word recognition in reading disabled children. Journal of Educational Psychology, 89, 159-169.

Metsala, J. L. (1999). Young children's phonological awareness and nonword repetition as a function of vocabulary development. Journal of Educational Psychology, 91, 3-19.

Mody, M., Studdert-Kennedy, M., \& Brady, S. (1997). Speech perception deficits in poor readers: Auditory processing or phonological coding. Journal of Experimental Child Psychology, 64, 199-231. 
Poulsen: Input processing in dyslexia

Nation, K. (2005). Picture naming and developmental reading disorders. Journal of Research in Reading, 28, 28-38.

Nation, K., Marshal, C. M., \& Snowling, M. J. (2001). Phonological and semantic contributions to children's picture naming skill: Evidence from children with developmental reading disorders. Language and Cognitive Processes, 16, 241-259.

Nickels, L., \& Howard, D. (1995). Phonological errors in aphasic naming: Comprehension, monitoring and lexicality. Cortex, 31, 209-237.

Nicolson, R. I., \& Fawcett, A. J. (1994). Reaction times and dyslexia. Quarterly Journal of Experimental Psychology, 47A, 29-48.

Pasquini, E. S., Corriveau, K. H., \& Goswami, U. (2007). Auditory processing of amplitude envelope rise time in adults diagnosed with developmental dyslexia. Scientific Studies of Reading, 11, 259-286.

Ramus, F., Rosen, S., Dakin, S. C., Day, B. L., Castellote, J. M., White, S., et al. (2003). Theories of developmental dyslexia: Insights from a multiple case study of dyslexic adults. Brain, 126, $841-865$.

Ramus, F., \& Szenkovits, G. (2008). What phonological deficit? Quarterly Journal of Experimental Psychology, 61, 129-141.

Richardson, U., Thomson, J. M., Scott, S. K., \& Goswami, U. (2004). Auditory processing skills and phonological representation in Dyslexic children. Dyslexia, 10, 215-233.

Rosen, S. (2003). Auditory processing in dyslexia and specific language impairment: Is there a deficit? What is its nature? Does it explain anything? Journal of Phonetics, 31, 509-527.

Scarborough, H. S. (1998). Early identification of children at risk for reading disabilities. In B. K. Shapiro, P. J. Accardo, \& A. J. Capute (Eds.), Specific reading disability: A view of the spectrum (pp. 75-119). New York: York Press.

Snowling, M. J. (2000). Dyslexia (2nd ed.). Oxford: Blackwell.

Snowling, M. J., Goulandris, N., Bowlby, M., \& Howell, P. (1986). Segmentation and speech perception in relation to reading skill: A developmental analysis. Journal of Experimental Child Psychology, 41, 489-507.

Snowling, M. J., van Wagtendonk, B., \& Stafford, C. (1988). Object-naming deficits in developmental dyslexia. Journal of Research in Reading, 11, 67-85.

Søegård, A., \& Petersen, S. P. B. (1974). OS-400. Ordstillelasningsprøve. En test til vurdering af børns begyndende tolkning af trykte verbale symboler. Copenhagen: Dansk Psykologisk Forlag.

Stone, B., \& Brady, S. (1995). Evidence for phonological processing deficits in less-skilled readers. Annals of Dyslexia, $45,51-78$.

Swan, D., \& Goswami, U. (1997). Picture naming deficits in developmental dyslexia: The phonological representation hypothesis. Brain and Language, 56, 334-353.

Szenkovits, G., \& Ramus, F. (2005). Exploring dyslexics' phonological deficit I: Lexical vs sub-lexical and input vs output processes. Dyslexia, 11, 253-268.

Thomson, J. M., Ben Fryer, J. M., \& Goswami, U. (2006). Auditory and motor rhythm awareness in adults with dyslexia. Journal of Research in Reading, 29, 334-348.

Wolf, M., O'Rourke, A. G., Gidney, C., Lovett, M., Cirino, P., \& Morris, R. (2002). The second deficit: An investigation of the independence of phonological and naming-speed deficits in developmental dyslexia. Reading and Writing, 15, 43-72.

Yopp, H. K. (1988). Thevalidity and reliability of phonemic awareness tests. Reading Research Quarterly, 23, 159-177. 